\title{
DIAGNÓSTICO DA COMPOSIÇÃO ARBÓREA DA CIDADE DE ISRAELÂNDIA-GO, BRASIL
}

\author{
Jéssica Silva Lara ${ }^{1}$, Elis Dener Lima Alves ${ }^{2}$, Fernanda Melo Carneiro ${ }^{3}$
}

\section{RESUMO}

As áreas arborizadas melhoram a qualidade do ar e permitem a preservação da biodiversidade local. A arborização é um processo que exige planejamento, pois aspectos como o porte e a origem das espécies ou até mesmo a estrutura das cidades devem ser considerados quando se pretende arborizar uma área. Esse trabalho teve como objetivo diagnosticar a arborização urbana do município de Israelândia-GO. Foi realizado um censo em todas as ruas do município. Além disso, comparamos as imagens do Google Earth de 2008 com o censo realizado no ano de 2012 para detectar a permanência bem com a inserção de novas espécies, foi feita uma análise descritiva do levantamento realizado, e calculado o índice de diversidade de Shannon e a equitabilidade para as todas as ruas do município. O município possui menos que 1 árvore por habitante. Contudo, as ruas apresentaram uma alta riqueza de espécies (58 espécies) com a predominância de espécies nativas. Durante o período analisado ocorreu maior inserção de espécies do que a retirada. A arborização da cidade é dominada por espécies nativas do Brasil, e a manutenção da arborização da cidade consiste basicamente na inserção de novas espécies o que já favorece a biodiversidade local.

Palavras-chave: Arborização; Centros urbanos; Espécies arbóreas; Nativa; Exótica.

Recebido em 26.03.2013 e aceito em 22.04.2014

1 Bióloga, formada pela Universidade Estadual de Goiás. Email: jessica.go2007@hotmail.com

2 Geógrafo, Doutorando em Ciências da Engenharia Ambiental da USP. São Carlos/SP. Email: elisdener@ usp.br

3 Bióloga, Drª.., Professora Titular da Universidade Estadual de Goiás. Iporá/GO. Email: fernanda.carneiro@ueg.br 


\title{
ARBOREAL COMPOSITION DIAGNOSTIC IN ISRAELÂNDIA, GOIÁS, BRASIL
}

\begin{abstract}
Urban afforestation improves air quality and allows the local biodiversity conservation. Afforestation process requires planning, thus aspects such as the size and the origin of species or even the structured of the city should be consider. This study was produce a diagnostic of the urban afforestation in Israelândia, Goiás. For this reason, we did a census in all the streets of the city. After, we compere the Google Earth image from 2008 and the census in 2012 to detect the permanence and the insertion of the new individuals. A descriptive analyses and some diversity metrics (e.g.: richness, evenness, Shannon diversity index) were calculate to understanding the species distribution pattern in urban area. There are less than one individual by inhabitant in Israelândia. However, the streets showed a high species richness, with the predominance of native species. Also was inserted more species than removed. In summary, the afforestation in the city studied is dominate by Brazilian native species and a maintained in the urban afforestation consist basically in the insertion of the new species, which already improve the local biodiversity.
\end{abstract}

Keywords: Afforestation; Urban area; Wooded species; Native; Exotic.

\section{INTRODUÇÃO}

Nas últimas décadas as discussões sobre o meio-ambiente fizeram com que os habitantes das cidades mudassem a sua visão em relação a importância da arborização urbana (SALATINO, 2001). Antes o homem valorizava as árvores nas cidades apenas pelo seu valor ornamental (BONAMETTI, 2003), hoje a arborização urbana é vista como uma excelente aliada para o conforto das pessoas que residem nos centros urbanos (SIRVINSKAS, 1998). A arborização contribui para melhoria de aspectos como o microclima local (BONAMETTI, 2003), diminuição da poluição (PAIVA; GONÇALVES, 2002), descompactação do solo (CADORIN; MELLO, 2011) e atenuação da poluição sonora (SIRVINSKAS, 1998). 
Entretanto, para que os benefícios da arborização urbana sejam alcançados em sua totalidade e prejuízos ecológicos e econômicos no ecossistema urbano sejam evitados, as espécies vegetais devem ser inseridas de forma planejada (LIRA-FILHO; MEDEIROS, 2006). Os prejuízos ecológicos advindos da arborização sem planejamento consistem em perdas na biodiversidade que podem ser causadas pela falta de abrigo e alimento adequado a fauna vizinha a esses lugares (BRUN et al., 2007). A inserção de plantas exóticas sem estudo prévio também pode gerar mudança nas características naturais do ecossistema, com perdas na biodiversidade (ZILLER, 2001). Assim como a inserção de muitos indivíduos da mesma espécie, que pode acarretar em uma rápida perda de biodiversidade caso esta espécie seja vulnerável ao acometimento por pragas e doenças (SILVA-FILHO; BORTOLETO, 2005). Quanto ao aspecto econômico, árvores de menor tamanho por exemplo, podem significar menor frequência de poda e economia da manutenção das cidades. Além disso, uma cidade bem arborizada pode vender créditos de carbono e formar verdadeiros bancos genéticos com espécies nativas e raras o que é econômica e ecologicamente bastante propício (KAGEYAMA; CASTRO, 1989).

Assim, para o planejamento da arborização urbana é primordial considerar a adequabilidade dessas plantas ao seu habitat como a disponibilidade de água e radiação solar (MILANO, 1987); a paisagem urbana em que as plantas serão inseridas (TARNOWSKI, 1991) e o tipo de vegetação (frutífera, forma de vida ou nativa/exótica) a ser utilizada (BLUM et al., 2008). Evitando a simples importação de soluções de outros locais e, principalmente, de regiões fitogeográficas distintas (SILVA et al., 2007). Contudo, na maioria das cidades como a estudada por nós, a arborização ainda ocorre de forma desorganizada e sem um estudo adequado de quais espécies devem ser inseridas nas áreas urbanas (BONAMETTI, 2003). Desse modo, esse trabalho tem como objetivo diagnosticar as condições da arborização urbana do município de um município de Goiás abordando aspectos como a distribuição espacial atual das espécies, a densidade, a diversidade arbórea e a dominância com intuito de orientar futuras urbanizações.

\section{MATERIAIS E MÉTODOS}

\section{Área de Estudo}

A área inventariada situa se na cidade de Israelândia, localizada na mesorregião do Centro Goiano (IBGE, 2010), nas coordenadas de $16^{\circ} 19^{\prime}$ 04" Latitude Sul e 50 $54^{\prime} 2^{\prime \prime}$ 
Longitude Oeste, altitude média de 378 metros (Figura 1). O município possui uma população de 2887 habitantes com área territorial é de $577 \mathrm{~km}^{2}$ (IBGE, 2010). Enquanto que a cidade possui área territorial de $0,9 \mathrm{~km}^{2}$ e população urbana de 2249 habitantes. O clima de Israelândia de acordo com a classificação de Koopen se enquadra como Tropical Semiúmido, apresentando precipitação média de $1586 \mathrm{~mm}$. A vegetação da região na qual se localiza a área urbana do município era originalmente coberta por cerrado stricto sensu (FARIA, 2006).

Figura 1. Área de estudo, perímetro urbano de Israelândia, Goiás

Figure 1. Study area, urban perimeter in the Israelândia, Goiás
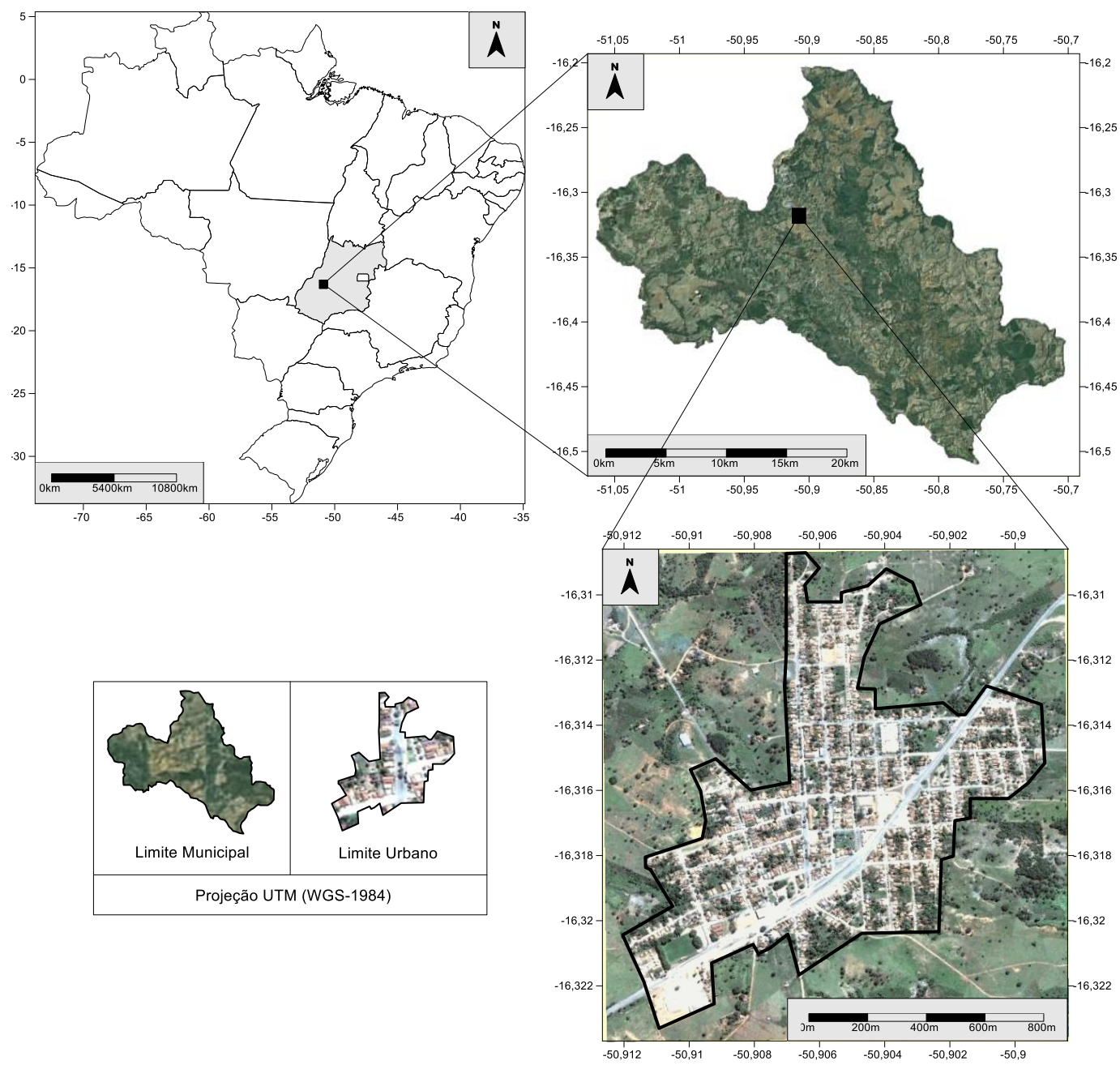

\section{Coleta de dados}

O levantamento das espécies arbóreas foi censitário, ou seja, foi realizado percorrendo todas as ruas da cidade. Para localização das vias públicas foram utilizadas imagens do Google Earth geo-referenciadas. As árvores foram identificadas individualmente 
pelo nome científico e popular da espécie seguido pelo nome da rua em que está inserido. Os dados foram coletados no período de junho a julho de 2012. Com intuito de analisar as mudanças da composição arbórea foi utilizada a imagem do Google Earth de 2008 juntamente com a averiguação em campo, a partir dessa comparação foi possível analisar os locais onde houve retirada das árvores, bem como onde houve inserção de novas mudas.

\section{Análise de dados}

Os dados do inventário foram analisados quantitativamente por meio da análise individuo/comprimento da rua, riqueza específica, e índice de Shannon. A relação indivíduo/comprimento rua foi calculada conforme a equação 1.

$$
C / I=\frac{c}{N} \quad(\text { Equação } 1)
$$

Em que (c) representa o comprimento da rua e $(N)$ o número de indivíduos arbóreos. Quanto menor for essa relação maior será o número de árvores por unidade métrica. $A$ riqueza corresponde ao número total de táxons presentes nas ruas da cidade.

O índice de Shannon, também chamado de índice de Shannon-Wiener, é um dos vários índices de diversidade usados para medir a diversidade em dados categóricos. Tratase da informação entrópica da distribuição, tratando espécies como símbolos e o tamanho da respectiva população como uma probabilidade. A vantagem desta medida de heterogeneidade é que ela leva em consideração o número das espécies e sua equitabilidade (URAMOTO et al., 2005; MELO, 2008). Esse índice é expresso na equação 2.

$$
H^{s}=-\sum_{i=1}^{S} p_{i} \times \ln p i
$$

Em que $S$ é o número de espécies, chamado também de riqueza e $p_{i}$ a abundância relativa de cada espécie, calculada pela proporção dos indivíduos de uma espécie pelo número total dos indivíduos na comunidade. A riqueza, e o índice de Shannon foram calculados no programa PAST (HAMMER et al., 2001). 


\section{RESULTADOS E DISCUSSÃO}

Nas vias públicas da cidade foram identificadas 58 espécies, das quais 19 são exóticas e 39 são nativas. O número de espécies encontradas pode ser considerado elevado quando comparado a cidades de grande porte como Assis-SP com 54 espécies (ROSSATTO et al., 2008), Campos do Jordão-SP com 32 espécies (ANDRADE, 2002). Por outro lado, em cidades similares a Israelândia, como Goiandira-GO, Pires et al. (2010) inventariou 105 espécies.

Observou-se alta variabilidade nos índices de diversidade entre as ruas da cidade, o que indica que as ruas são uma unidade de manejo adequada. Ruas arborizadas melhoram aspectos como paisagismo e a preservação de espécies, tanto da fauna como da flora (SILVA-FILHO; BORTOLETO, 2005). A maior diversidade de espécies foi encontrada na rua Minas Gerais (RMG, Tabela 1) enquanto a menor diversidade foi encontrada na rua 15 de Novembro (R15N). Os valores de diversidade observados foram inferiores aqueles observados para Assis-SP (ROSSATTO et al., 2008). A riqueza também variou muito entre as ruas, com valores entre 2 e 24 espécies (Tabela 1).

Tabela 1. Descrição da diversidade arbórea encontrada nas ruas de Israelândia, Goiás. Número de espécies (R), número de indivíduos (D), índice de diversidade de Shannon $(\mathrm{H})$ para cada rua da cidade

Table 1. Description of the arboreal diversity found in the streets of Israelândia, Goiás. For each street were calculated the Richness (R), density (D), Shannon's diversity index $(\mathrm{H})$

\begin{tabular}{lllll}
\hline Nome da Rua (Street) & Sigla (code) & Riqueza (R) & Indivíduos (D) & Shannon (H) \\
\hline Rua Jovito Soares & RJS & 24 & 224 & 1,63 \\
Rodovia GO-060 & GO60 & 11 & 216 & 1,81 \\
Rua 3 de Abril & R3A & 15 & 144 & 0,99 \\
Rua Juscelino Kubitschek & RJK & 19 & 134 & 1,96 \\
Rua Pedro Lodovico Texeira & RPLT & 12 & 133 & 1,21 \\
Rua Goiás & RG & 17 & 92 & 1,82 \\
Rua Santa Luzia & RSL & 14 & 82 & 1,65 \\
Rua Antônio Claudio & RAC & 13 & 78 & 1,59 \\
Rua 7 de Setembro & R7S & 8 & 63 & 1,34 \\
Rua Ananias Barroso & RAB & 8 & 59 & 1,26 \\
Rua Rio Claro & RRC & 9 & 58 & 1,71 \\
Rua Araguaia & RA & 12 & 50 & 1,73 \\
Rua Tocantins & RT & 6 & 50 & 1,12 \\
Rua dos Garimpeiros & RDG & 9 & 42 & 1,67 \\
Minas Gerais & RMG & 15 & 41 & 2,22 \\
Rua 1 & R1 & 9 & 38 & 1,25 \\
Rua Ambrósio de Moreira Carvalho & RAMC & 10 & 34 & 1,48 \\
Rua João Firmino Silva & RJFS & 6 & 29 & 1,37
\end{tabular}




\begin{tabular}{lllll} 
Rua Teófilo Machado & RTM & 11 & 27 & 2,01 \\
Rua Melquiades Antônio Claudio & RMAC & 2 & 26 & 0,65 \\
Rua 3 & R3 & 6 & 24 & 1,27 \\
Rua Joana Caetano & RJC & 7 & 22 & 1,81 \\
Rua Joana Ribeiro & RJR & 6 & 22 & 1,2 \\
Rua 15 de Novembro & R15N & 2 & 20 & 0,42 \\
Rua Bahia & RB & 10 & 20 & 2,06 \\
Rua Caiapó & RC & 5 & 15 & 1,29 \\
Rua Paranaíba & RP & 5 & 14 & 1,22 \\
Rua 2 & R2 & 6 & 13 & 1,41 \\
Rua José A. Costa & RJAC & 3 & 9 & 0,85 \\
\hline
\end{tabular}

O número total de árvores (indivíduos) das vias públicas de Israelândia foi de 1788 indivíduos, o que significa aproximadamente 0,8 árvore para cada habitante. A UNESCO (Organização das Nações Unidas para a Educação) recomenda 2 árvores para cada habitante ou $12 \mathrm{~m}^{2}$ de área verde por habitante (DANTAS; SOUZA, 2004). Embora a maioria das cidades esteja bem abaixo desse índice, em Goiânia, esses valores estão bem acima do recomendado (PIRES et al., 2010). A razão entre o comprimento da rua e o número de indivíduos está expressa por rua na figura 2. Quanto menor o valor dessa razão (ver equação 1) mais arborizada é essa rua. Assim, as ruas melhor arborizadas proporcionalmente no município de Israelândia são Melquiades Antônio Claúdio, Joana Caetano, 15 de Novembro e a Rua 1 (Figura 2).

Figura 2. Relação entre o comprimento da rua e o número de indivíduos arbóreos Figure 2. Ratio of the Length street and number of individuals

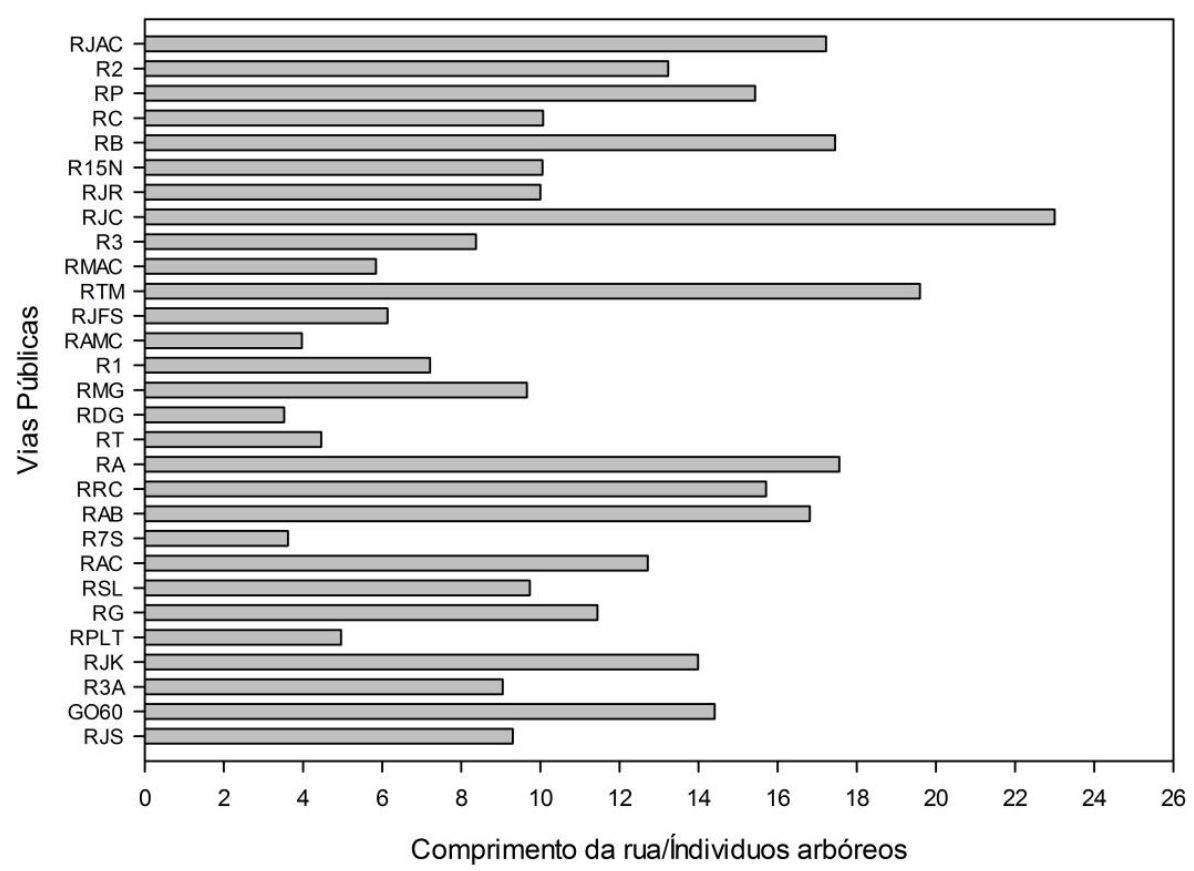


Embora na maioria das cidades brasileiras as espécies exóticas sejam predominantes (BLUM et al., 2008), na cidade de Israelândia elas constituíram a minoria da composição arbórea, representando 33.3\% das espécies encontradas (Figura 3). Muitas das plantas exóticas podem causar perda da biodiversidade nativa de plantas e animais, pois se adaptam ao clima local e se reproduzem rapidamente, ou seja, apresentam maior sucesso no ambiente introduzido do que as espécies nativas (BERNARDY et al., 2011).

As espécies nativas foram dominantes nas ruas de Israelândia, contudo, é importante ressaltar que essa dominância se deve principalmente a uma única espécie (Figura 3, 4A). Licantia tomentosa (916 indivíduos) foi a espécie dominante em IsraelândiaGO, assim como observado nas cidades de Assis-SP (ROSSATTO et al., 2008) e Jaboticabal-SP (SILVA-FILHO et al., 2002). As plantas nativas são excelentes para arborização, pois representam um meio de preservação da flora nativa, servem de fonte de alimentos para a fauna e ainda são adaptadas as condições ambientais. Além disso, as plantas nativas representam um meio de preservar a biodiversidade (KAGEYAMA; CASTRO, 1989). Entretanto, no Brasil, não se tem muito o hábito de se plantar espécies nativas (BLUM et al., 2008).

Figura 3. Principais espécies arbóreas nativas e exóticas nas ruas de Israelândia. O (*) indica as espécies exóticas

Figure 3. Principal species found in the urban area of the Israelândia. The asterisk $\left(^{*}\right)$ represents the exotics species

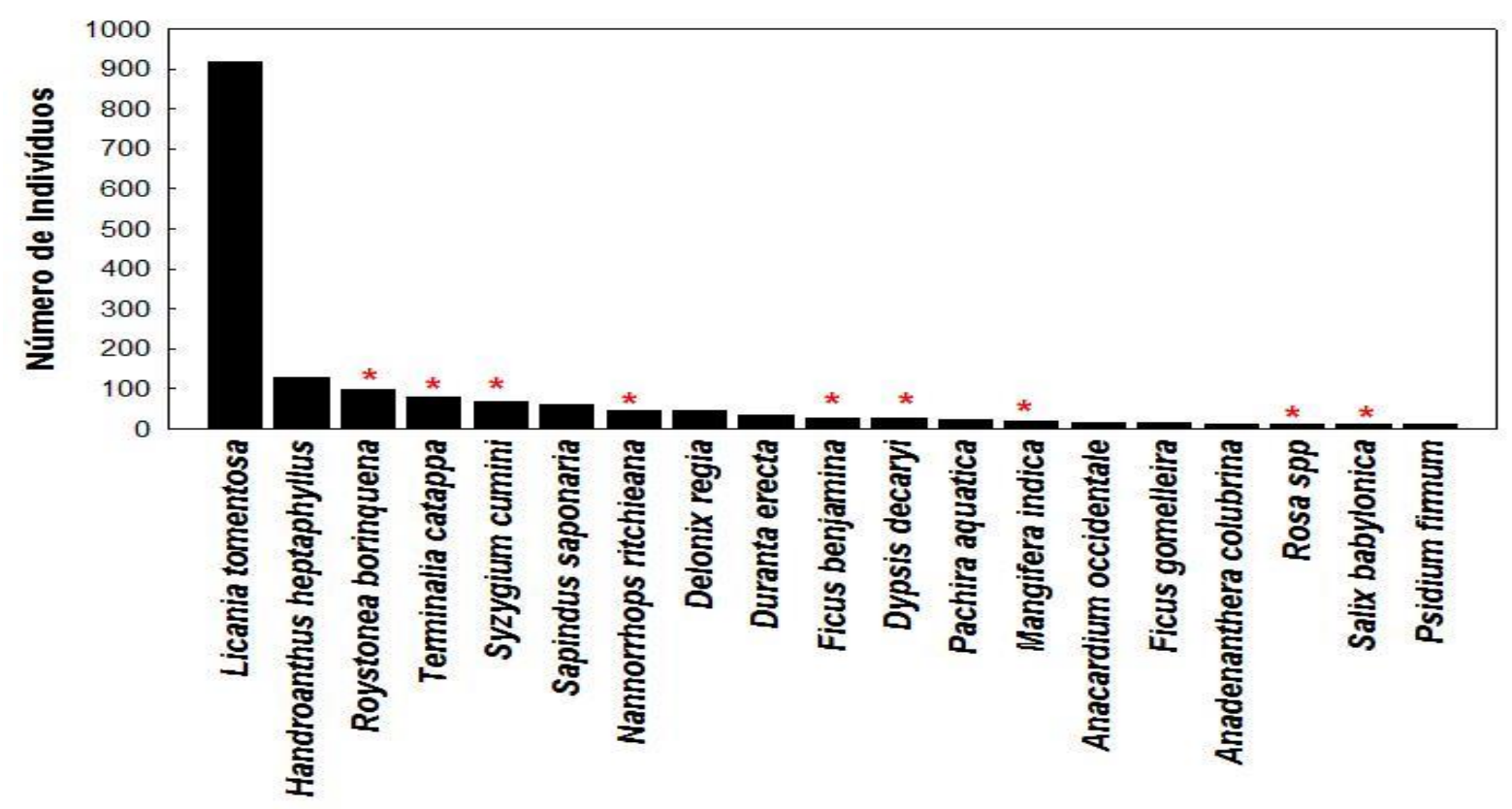


Em relação às espécies nativas e exóticas a espécie de maior frequência encontrada foi a espécie nativa oiti (Figura 4A) que é uma árvore bastante utilizada em arborização urbana, ela chega a medir até 10 metros de altura e possui as raízes pivotantes, folhas perenifólicas e a propagação ocorre por semente (LULA et al., 2010). O oiti também foi a espécie mais abundante encontrada na arborização urbana de Jaboticabal - SP (SILVAFILHO et al., 2002). A Palmeira Imperial (Figura 4C) foi a espécie exótica mais encontrada nos canteiros centrais e em algumas calçadas da cidade, já o Tamarindo (Tamirindus indica) está entre as espécies exóticas de menor frequência nas ruas (Figura 4B). A Palmeira Imperial é uma árvore nativa de Porto Rico, chega a medir 30 metros de comprimento, e por isso é mais utilizada nos canteiros centrais das cidades, ou seja, locais espaçosos e expostos. A Palmeira Imperial é uma árvore frutífera, no qual seus frutos servem de alimentos aos pássaros e o pólen é utilizado como fonte de alimentos das abelhas (LORENZI et al., 1996). O Tamarindo é uma árvore originaria da Índia, possui a copa bem volumosa, é de porte alto, e também é frutífera, porém não é muito comum ser utilizada na arborização e sim em pomares (LORENZI et al., 2003).

Figura 4. Oiti (Licania tomentosa) A, Tamarindo (Tamirindus indica) B, Palmeira Imperial (Roystonea borinquea) C, Ingá (Inga vera wild) D

Figure 4. Oiti (Licania tomentosa) A, Tamarind (Tamirindus indica) B, Royal Palm (Roystonea borinquea) C, Ingá (Inga vera wild) D

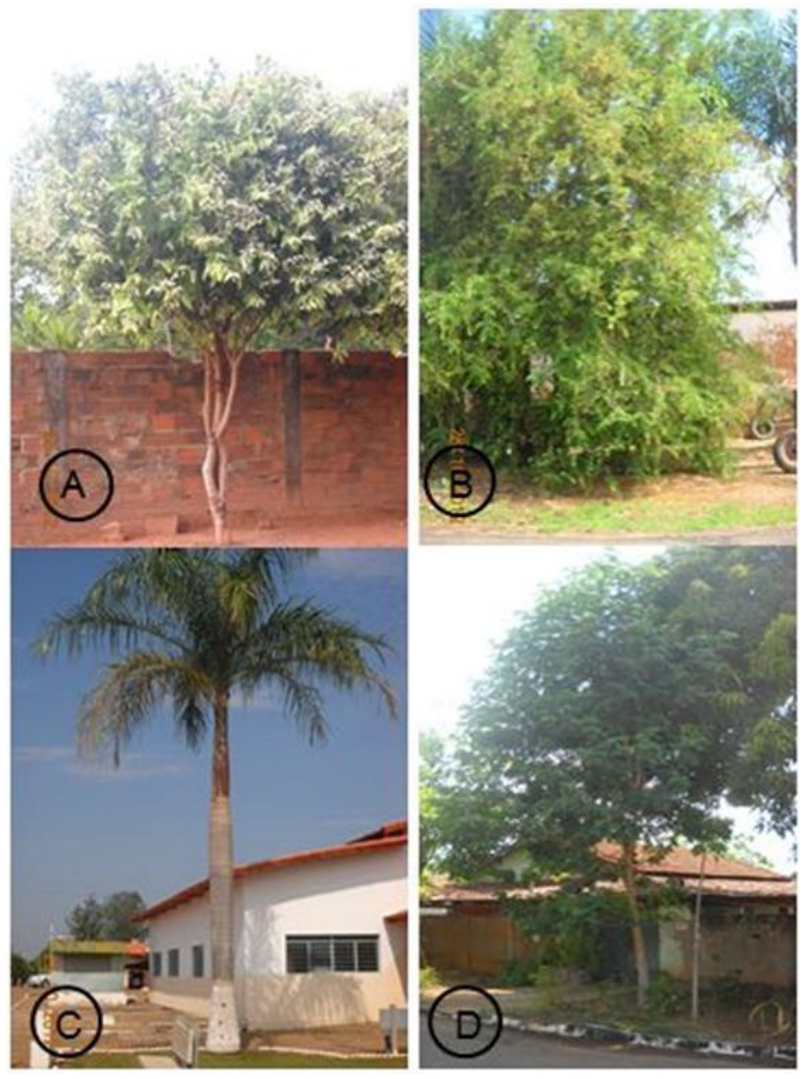


Para que sejam inseridas novas espécies arbóreas nos canteiros centrais, calçadas e ruas das cidades é necessário que se plante uma nova muda antes que faça a retirada da mesma. Ainda é necessário realizar um estudo sobre as condições em que a planta se encontra para que assim possa realizar a retirada do vegetal de forma correta (SILVAFILHO et al., 2002). Entre os anos de 2008 e 2012 foram retirados 107 indivíduos e inseridos 257 novos. Assim, nas ruas de Israelândia a retirada de árvores está sendo feita com subsequente replantio (Figura 5). Contudo é possível notar que nem sempre o plantio ocorreu na mesma área, ou seja, a inserção de novas plantas não ocorreu onde aconteceu a retirada. Ademais, não é necessário a retirada das espécies arbóreas para a inserção de novas espécies. As ruas as quais houve o maior número de árvores retiradas foram RPLT e a RJS. Nessas ruas as árvores foram retiradas especialmente dos canteiros centrais sem o replantio de novas árvores. As ruas G0060 e R3A apresentaram maior inserção de árvores em locais desprovidos de vegetação.

Figura 5. Área de estudo com a representação do local e do número de indivíduos retirados em vermelho e inseridos em verde entre os anos de 2008 e 2012

Figure 5. Species that were excluded (in red), and inserted (in green) between the years of 2008 and 2012, Israelândia, Goiás

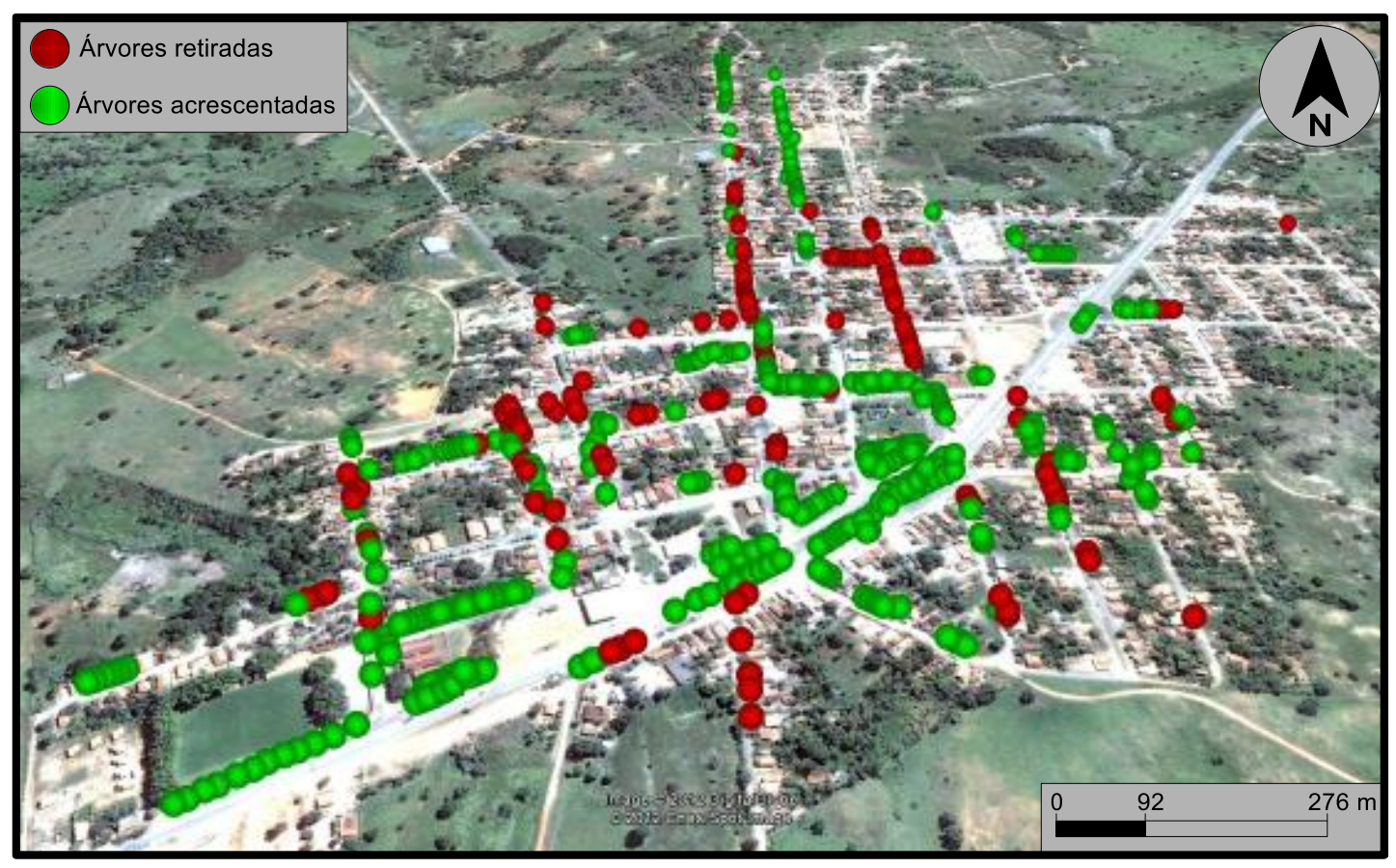




\section{CONCLUSÕES}

A cidade de Israelândia possui uma arborização urbana regular, apresentando mais espécies e indivíduos que outras cidades brasileiras. A maior frequência arbórea encontrada foi de espécies nativas, o que para a biodiversidade é bastante benéfico. Em geral, a cidade tem apresentado um manejo da arborização, pois o replantio durante o período analisado foi maior que a retirada das árvores. Contudo, é importante ressaltar que nem sempre o replantio tem sido feito na mesma área em que foram retiradas as espécies e que não há necessidade da retirada das espécies arbóreas para o replantio de novas espécies. A riqueza de espécies (árvores) variou bastante entre as ruas, e as ruas mais bem arborizadas foram às ruas menores.

\section{AGRADECIMENTOS}

A Fundação de Amparo à Pesquisa do Estado de São Paulo, FAPESP, Brasil pela bolsa de doutorado concedida ao segundo autor (Alves, E. D. L.). A prefeitura de Israelândia pela disponibilização de informações.

\section{REFERÊNCIAS}

ANDRADE, T. O. Inventário e análise da arborização viária da Estância turísticas de campos de Jordão, SP. 2002. 112 f. Dissertação (Mestrado em Agronomia). ESALQ, USP, Piracicaba.

BERNARDY, K.; MENDES K. L.; SCHEIG, S.; COPATTI, E. C. O impacto de plantas exóticas para a biodiversidade e meio ambiente. In: XIX Seminário interinstitucional de ensino pesquisa e extensão, 2011, Cruz Alta, RS. Anais universidade no desenvolvimento regional, Universidade de Cruz Alta, 2011.

BLUM, C. T.; BORGO, M.; SAMPAIO, A. C. F. Espécies exóticas invasoras na arborização de vias públicas de Maringá-PR. Revista Brasileira de Arborização Urbana, v. 3, n. 2, p. 78-97, 2008.

BONAMETTI, J. Arborização urbana. Terra e Cultura, v. 19, n. 36, p. 51-55, 2003.

BRAGA, R.; CARVALHO, P.F. C. Recursos hídricos e planejamento urbano e regional. Laboratorio de planejamento municipal, IGGE-UNESP, Rio Claro, 2003. 
BRUN, K. G. F.; LINK, D.; BRUN, J. E. O emprego da arborização na manutenção da biodiversidade de fauna em áreas urbanas. Revista da Sociedade Brasileira de Arborização Urbana, v. 2, n. 1, p. 117-127, 2007.

CADORIN, A. D.; MELLO A. N. Efeitos da Impermeabilização dos solos sobre a arborização no município de Pato Branco- PR. Synergismus Scyentifica, v. 6, n. 1, 2011.

DANTAS, I. C.; SOUZA, C. M. C. Arborização urbana na cidade de Campina Grande - PR; Inventário e suas espécies. Revista de Biologia e Ciências da Terra, v. 4, n.2, p. 1-19, 2004.

FARIA, S. M. K. Caracterização dos Remanescentes de Cerrado e suas relações com o uso e ocupação das terras da alta bacia do Rio Araguaia. 2006, 165 f. Dissertação (mestrado em Geografia) - Instituto de Estudos Sócio Ambientais, Universidade Federal de Goiás, Goiás.

HAMMER, Ø; HARPER, D. A. T., RYAN, P. D. PAST: Paleontological Statistics Software Package for Education and Data Analysis. Palaeontologia Electronica, v. 4, n. 1, p. 1-9. 2001.

IBGE - INSTITUTO BRASILEIRO DE GEOGRAFIA E ESTATÍSTICA, 2010. Cidades@. Disponível em: <http://www.ibge.gov.br/cidadesat/default.php> Acesso em 10 nov. 2012.

KAGEYAMA, Y. P.; CASTRO, A. F. C. Sucessão secundaria, estrutura genética e plantações de espécies arbóreas nativas. IPEF, n. 41/42, p. 83-93,1989.

LIRA-FILHO, A. J.; MEDERIRO, S. A. M. Impactos adversos na avifauna pelas as atividades de arborização urbana. Revista de Biologia e Ciências da Terra, v. 6, n. 2, p. 375-390, 2006.

LORENZI, H. SOUZA, H. M. de, COSTA, J. T. de M., CERQUEIRA, L. S. C. de, BEHR, N. V. Palmeiras no Brasil Nativas e Exóticas. São Paulo: Nova Odessa, 1996.

LORENZI, H.; SOUZA, H. M. de; TORRES, M. A. V.; BACHER, L. B. Árvores exóticas no Brasil madeireiras, ornamentais e aromáticas. São Paulo: Nova Odessa, 2003.

LULA, R. L.; SILVA, G. C. P.; NASCIMENTO, S. C. S.; OLIVEIRA, S.P. R.; SILVA, F. G. Caracterização físico químico do óleo de licania salzmonni para produção de biodiesel. IV Congresso Brasileiro de Mamona e I Simpósio Internacional de Oleaginosas Enérgeticas. João Pessoa, Pernambuco, 2010.

MAGURRAN, A.F. Measuring Biological diversity. Blackwell Publ, 2004, 256p. 
MELO, A. S. O que ganhamos "confundindo" riqueza de espécies e equabilidade em um índice de diversidade? Introdução. Biota Neotropica, v. 8, n.3, p. 21-27, 2008.

MENEGHETTI, G. I. P. Estudo de dois métodos de amostragem para inventário da arborização de ruas dos bairros da horta do município de Santos- SP. Dissertação do mestrado em Recursos Florestais, 2003.

MILANO, M. S. O planejamento da arborização, as necessidades de manejo e tratamentos culturais das arvores de ruas de Curitiba-PR. Revista Floresta, v. 17, n. 12, 15-21. 1987.

PAIVA, H. N.; GONÇALVES, W. Floresta Urbana: planejamento para melhoria da qualidade de vida. Viçosa: Aprenda Fácil Editora, 2002, 180p.

PIRES, N. A. M. T., MELO, M. DA S., OlIVEIRA, D. E., \& XAVIER-SANTOS, S. A arborização urbana do município de Goiandira/GO - Caracterização quali-quantitativa e proposta de manejo. Revista Brasileira de Arborização Urbana, v. 5, n. 3, 185-205. 2010.

ROSSATTO, R. D.; TSUBOY, F. S. M.; FREI, F. Arborização urbana da cidade de Assis-SP: Uma abordagem quantitativa. Revista Brasileira de Arborização Urbana, v. 3, n. 3. 2008.

SALATINO, A. Nós e as plantas. Revista Brasileira de Botânica, v. 24, n. 4 (suplemento), p. 483-490, 2001.

SHANNON, C. E.; WEAVER, W. The mathematical theory of communication. Urbana, Illinois University Press, 1963, 177p.

SILVA-FILHO, D. F.; PIZETTA, P. U. C.; ALMEIDA, J. B. S. A.; PIVETTA, K. F. L.; FERRAUDO, A. S. Banco de dados para cadastro, avaliação e manejo da arborização em vias públicas. Revista Árvore, v. 26, n. 5, 629-642. 2002.

SILVA-FILHO, D. F.; BORTOLETO, S. Use of diversity indicators in a street arborization management plan for Águas de São Pedro - SP, Brazil. Revista Árvore, v. 29, n. 6, p. 973982. 2005.

SILVA, L. M.; HASSE, I.; MOCCELIN, R.; ZBORALSKI, A. R. Arborização de vias públicas e a utilização de espécies exóticas: o caso do bairro centro de Pato Branco/PR. Scientia Agraria, v. 8, n. 1, p. 47-53, 2007.

SIRVINSKAS, P. L. Tutela penal do meio ambiente. Editora Saraiva, 1998. São Paulo. 
TARNOWSKI, L.C. Preservação do meio ambiente e a arborização. Nema, 3ํㅡㄹ Encontro Nacional de Estudos sobre o Meio Ambiente. Anais Londrina; Universidade Estadual de Londrin- UEL, p. 530-531, 1991.

URAMOTO, K.; WALDER, J. M. M.; ZUCCHI, R. A. Análise Quantitativa e distribuição de populações de espécies de Anastrepha (Diptera: Tephritidae) no campus Luiz de Queiroz, Piracicaba, SP. Neotropical Entomology, v. 34, n.1, p. 33-39, 2005.

ZILLER, S. R. Os processos de degradação ambiental originados por plantas invasoras. Revista Ciência Hoje, n. 178, dez. 2001. 